\title{
Low-priority Tuberculosis Subject
}

National Cancer Institute

\section{Source}

National Cancer Institute. Low-priority Tuberculosis Subject. NCI Thesaurus. Code C102662.

An individual that has had limited exposure to an individual with tuberculosis and has a low probability of having had a recent infection. 